\title{
Testis structure, spermatogenesis and sperm morphology in pipefishes of the genus Syngnathus
}

\author{
Francesca Biagi, ${ }^{1}$ Francesca Piras,${ }^{2}$ Vittorio Farina, ${ }^{1}$ Marco Zedda, ${ }^{1}$ Emilio Mura, ${ }^{1}$ Antonello Floris, ${ }^{1}$ \\ Piero Franzoi, ${ }^{3}$ Anna Maria Fausto, ${ }^{4}$ Anna Rita Taddei ${ }^{5}$ and Marcella Carcupino ${ }^{2}$
}

\begin{abstract}
${ }^{1}$ Dipartimento di Medicina Veterinaria, Università di Sassari, via Vienna 2, 07100, Sassari, Italy; ${ }^{2}$ Dipartimento di Scienze dalla Natura e del Territorio, Università di Sassari, Via Muroni 25, 07100, Sassari, Italy; ${ }^{3}$ Dipartimento di Scienze Ambientali Informatica e Statistica, Università Ca' Foscari di Venezia, Dorsoduro 2137, 30123, Venezia, Italy; ${ }^{4}$ Dipartimento per l'Innovazione nei sistemi Biologici, Agro-alimentari e Forestali, Università della Tuscia, Via San Camillo De Lellis, 01100, Viterbo, Italy; ${ }^{5}$ Centro Interdipartimentale di Microscopia Elettronica (CIME), Università della

Tuscia, Largo dell’Università snc, O1100, Viterbo, Italy
\end{abstract}

\section{Keywords:}

semicystic spermatogenesis, Syngnathidae, germ cells

Accepted for publication:

17 October 2014

\begin{abstract}
Biagi F., Piras F., Farina V., Zedda M., Mura E., Floris A., Franzoi P., Fausto A.M., Taddei A.R. and Carcupino M. 2016. Testis structure, spermatogenesis and sperm morphology in pipefishes of the genus Syngnathus. - Acta Zoologica (Stockholm) 97: 90-101.
\end{abstract}

Testes, spermatogenesis and sperm morphology have been analysed in four species of the Syngnathus genus. All species show testes of unrestricted lobular type, characterized by a single germinal compartment, with central lumen, and an external tunica albuginea. The spermatogenesis occurs throughout a process of semicystic type, in which germinal spermatocysts open precociously, so germ cells complete maturation in the testis lumen. Amongst them, aflagellate and flagellate multinucleate cells are recognizable. This type of spermatogenesis may be therefore related to the reduced number of simultaneously mature sperm produced by syngnathids. Only one type of mature sperm has been identified in all examined species. It is always a monoflagellate cell, characterized by an elongated head. Elongated head has generally been correlated with the internal fertilization and/or to the production of spermatophore. As this is not the case of syngnathids, a possible function to explain the particularly elongated head of syngnathids is discussed.

Marcella Carcupino, Dipartimento di Scienze della Natura e del Territorio, Via Muroni 25, 07100 Sassari, Italy. E-mail: carcupin@uniss.it

\section{Introduction}

The array of reproductive strategies amongst teleosts is extraordinarily diverse and, amongst them, those of syngnathids are peculiar. In this teleosts family, eggs are laid by the females on or into the male brooding structure, which has, according to the species, a different localization and extraordinarily diverse morphology (see Wilson and Orr 2011). Egg fertilization is assumed to take place after their deposition, but how sperm move to reach the eggs has not been completely understood yet.

In fish, adaptations for sperm transfer have involved the modification of the testis and sperm morphology (Burns et al. 1995, 2000), as well as the transformation of male fins or other body regions into intromittent organs (Meisner 2005; Burns and Weitzman 2006). The male reproductive apparatus of syngnathids still largely remains a mystery to investigators, and, at present, conflicting data are reported for both testis and sperm morphology.
Testes of restricted lobular and unrestricted tubular type have been reported in Microphis brachyurus lineatus (Kaup) (Miranda-Marure et al. 2004), Syngnathus abaster Risso and Syngnathus acus L. (Carcupino et al. 1999), respectively. In addition, in the last two species, the germinal epithelium has been reported to be organized in the typical spermatocysts (Carcupino et al. 1999), whereas in Syngnathus schlegeli Kaup, these structures seem to be absent, or at least, difficult to be recognized (Watanabe et al. 2000).

Large droplets-containing cells characterize the testis of several syngnathid species. These cells, however, are reported to have different localization. In $S$. schlegeli, they appear to be localized in the germinal epithelium only (Watanabe et al. 2000), whereas in $S$. abaster and $S$. acus, they have been also observed inside the lumen, where they have been interpreted as germinal cells in different developmental stages, associated with a semicystic spermatogenesis (Carcupino et al. 1999).

The functional sperm of most syngnathids examined up to now have been categorized as introsperm type (Watanabe 
et al. 2000; Van Look et al. 2007; Biagi et al. 2008; Dzyuba et al. 2008), which has elongated head and long flagellum, and is typical of internal fertilizing fish (Jamieson 1991). This type of sperm is the unique type found in a brackish water population of $S$. Abaster, $S$. acus and N. ophidion (Carcupino et al. 1999; Ah-King et al. 2006). Only one type of sperm has also been reported in $M$. brachyurus lineatus. In this species, however, sperm seem to be of the aflagellate type (MirandaMarure et al. 2004). Syngnathus schlegeli and Hippocampus kuda seem to have two sperm types: functional sperm of introsperm type and non-functional sperm of aquasperm type (Watanabe et al. 2000; Van Look et al. 2007). The latter, which is typical of external fertilizing fish (Jamieson 1991), is characterized by a large spherical head. Three different morphotypes of sperm, differing in flagellum length, head length and head wide, have been reported in a freshwater population of $S$. abaster (Dzyuba et al. 2008). Amongst them, however, only the longest seems to be functional.

To shed light on these topics, we analysed the male gonad of four internal brooder species belonging to the Syngnathus genus, using different light and electron microscopic techniques. We particularly intended to ascertain: (i) the testis structure and spermatogonia localization, (ii) the germinal epithelium organization, (iii) the morphology and localization of Leydig cells, and (iv) the modality of spermatogenesis and sperm structure.

\section{Materials and Methods}

\section{Samples}

Twenty-eight adult males belonging to the pipefishes species Syngnathus abaster $(n=24), S$. tenuirostris $(n=3), S$. typhle $(n=4)$ and $S$. acus $(n=4)$ were analysed.

$S$. abaster, the easiest species to be sampled, were collected in two Mediterranean lagoons (Cabras lagoon, in western Sardinia and Venice lagoon, Italy). S. tenuirostris and $S$. typhle were both collected in Venice lagoon. $S$. acus were collected in the sea near Alghero (Sardinia). All samples of the above species were captured during the reproductive period (MaySeptember).

Different analyses with different purposes were used. In particular, for the description of the general organization of the testes, the following analyses were performed:

Histological techniques. Eight entire reproductive apparatuses (two for each species) were dissected, fixed in aqueous Bouin's fixative, dehydrated in a graded ethanol series, cleared in Bioclear and finally embedded in paraffin wax. Sections $(5 \mu \mathrm{m})$ were stained with Mayer's Hemalum and Eosin (Mazzi 1977) and observed with a Zeiss Axiophot light microscope (ZEISS, Oberkochen, Germany).

In an attempt to observe a larger number of mature spermatozoa, hardly observable in thin sections of paraffinembedded samples, some thicker cryosections were tested.
Additional testes obtained from two males of $S$. abaster were fixed in $4 \%$ paraformaldehyde ( $\mathrm{pH} 7.4$ ) at $4{ }^{\circ} \mathrm{C}$. Then, samples were washed in $0.4 \mathrm{M}$ Sorenson's phosphate buffer (PBS) at least for $1 \mathrm{~h}$ (three changes of $20 \mathrm{~min}$ each). The testes were then transferred in $30 \%$ sucrose solution for 1 day. Afterwards, sections (20 $\mu \mathrm{m}$ thick), obtained using a cryostat (Microm Cryo-Star HM 560, Walldorf, Germany), were placed on electrostatically charged slides (Superfrost Plus, Menzel-Gläser) and stained with Haematoxylin and Eosin. After staining, all preparations were dehydrated in ethanol, mounted in Canada balsam and observed with a Zeiss Axiophot light microscopy. Digital images were obtained using a Canon Power Shot camera G2.

Transmission electron microscopy (TEM) for testis ultrastructure. Testes of both $S$. abaster and $S$. acus (two for each species) were dissected and fixed for $2 \mathrm{~h}$ in $4 \%$ paraformaldehyde- $5 \%$ glutaraldehyde buffered with sodium cacodylate $(0.1 \mathrm{M}, \mathrm{pH} 7.2)$. Specimens were then rinsed overnight in the same buffer, postfixed for $1 \mathrm{~h}$ in $1 \%$ osmium tetroxide buffered with sodium cacodilate, dehydrated gradually in ethanol and embedded in Epon 812 resin. Semi-thin and thin sections of $1 \mu \mathrm{m}$ and $80 \mathrm{~nm}$ thick, respectively, were cut with a Reichert Ultracut ultramicrotome. Semi-thin sections were stained with toluidine blue and then photographed with a Canon Power Shot G6 camera, mounted on Zeiss Axiophot light microscope. Thin sections were stained with uranyl acetate and lead citrate, observed and photographed with a Jeol Tem 1200 EX II transmission electron microscope (JEOL, Tokyo, Japan).

Fluorescent microscopy. To evidence the muscular fibres of the tunica albuginea, muscle actin was labelled with $\mathrm{Rh}-$ phalloidin. Two testes of $S$. abaster were removed in phosphate-buffered saline (PBS) and fixed for $1 \mathrm{~h}$ at $4{ }^{\circ} \mathrm{C}$ with freshly prepared $4 \%$ paraformaldehyde in $0.1 \mathrm{M}$ PBS, $\mathrm{pH}$ 7.4, thoroughly rinsed and permeated with Triton X-100. F-actin filaments were stained for $40 \mathrm{~min}$ at room temperature with Rh-phalloidin (Molecular probes, Eugene, Ore, USA) diluted $1: 100$. Nuclei were stained for $5 \mathrm{~min}$ with the nuclear dye DAPI ( $1 \mathrm{mg} / \mathrm{mL}$ in PBS, SIGMA). After final rinsing in PBS for $5 \mathrm{~min}$, the samples were mounted in a mixture of $5 \%$ PBS $+90 \%$ glycerol $+5 \%$ propyl gallate and observed in a LEICA DMI 6000B microscope connected to a TCS SP5 confocal scanning system equipped with laser 405 DIODE (UV), ARGON, HeNe $543, \mathrm{HeNe} 633$. Video images were collected using ' 10 and '40 lenses.

For the luminal cells and sperm morphology, the following analysis was used:

Light microscopy. To analyse the different types of cells free in the testicular lumen, two testes for each species were dissected and kept in acetic orcein for $24 \mathrm{~h}$, then gently squashed and observed with a Zeiss Axiophot light microscope. 
Moreover, to obtain isolated luminal cells, testes of further 10 males of $S$. abaster and one of $S$. typhle were isolated and open with forceps. A small aliquot $(20 \mu \mathrm{L})$ of $5 \%$ glutaraldehyde-fixed luminal cells was applied onto a coverslip precoated with polylysine (1 mg mL-1, Sigma P1274) and allowed to air-dry. Next, luminal cells adhering to the coverslip were stained with toluidine blue $0.1 \%$ in aqueous solution and observed with a Zeiss Axiophot light microscope (Zeiss). A pool of 60 polyflagellate cells, obtained from different slides of a single $S$. abaster specimen, were analysed to estimate the flagella numbers.

Scanning electron microscopy (SEM). The external morphology of cells free in the testicular lumen, including mature sperm, was analysed using an aliquot $(20 \mu \mathrm{L})$ of formalin-fixed luminal cells obtained from testes of $4 S$. abaster males and applied onto a coverslip precoated with polylysine. Next, luminal cells adhering to the coverslips were dehydrated using a graded ethanol series $(5 \%, 10 \%, 15 \%, 20 \%, 30 \%, 40 \%, 50 \%, 60 \%$, $70 \%, 80 \%, 90 \%, 95 \%$ and $100 \%$ ethanol) and critical-point dried (Bal-Tec CPD 030) Critical Point Dryer, goldpalladium coated and observed with (JEOL JSM 5200; Jeol) scanning electron microscope.

Fluorescent microscopy. To evidence both the cytoplasmic and flagella microtubules, aliquots $(20 \mu \mathrm{L})$ of luminal cells obtained from the testes of three males of Syngnathus abaster were applied onto a coverslip precoated with polylysine and allowed to dry. Then, the sample was fixed in methanol for $5 \mathrm{~min}$ at $-20^{\circ} \mathrm{C}$, permeated in acetone for $5 \mathrm{~min}$ at $-20{ }^{\circ} \mathrm{C}$ and rinsed in PBS. Fixed cells were then preincubated with PBS contains 1\% BSA (bovine serum albu$\mathrm{min}$ ) for $20 \mathrm{~min}$, incubated in monoclonal anti- $\alpha$-tubulin antibody, clone DM 1A (Sigma), diluted 1:400 for $1 \mathrm{~h}$ in the dark, then rinsed three times on PBS for $5 \mathrm{~min}$, postincubated in an anti-mouse-TRITH antibody (Sigma) diluted $1: 200$ for $1 \mathrm{~h}$ in the dark. Nuclei were stained for $5 \mathrm{~min}$ with DAPI. After final rinsing in PBS for $5 \mathrm{~min}$, the samples were mounted in a mixture of $5 \%$ PBS + $90 \%$ glycerol $+5 \%$ propyl gallate and observed in a LEICA DMI 6000B microscope connected to the confocal system.

Morphometry. To study the nuclear morphometry of the different luminal cells types, two samples of $S$. abaster processed with acetic orcein (see above) were analysed. Thirty nuclei per each cellular type were measured.

Furthermore, to study the morphometry of the spermatozoa, such as the length of both the head (including the nucleus and the midpiece) and flagellum, intact spermatozoa, stained with toluidine blue (see above) and obtained from the two species, $S$. abaster ( $n=200,20$ sperm per males) and $S$. typhle ( $n=17$, obtained by a single male) were analysed. Abnormal, broken or difficult to measure spermatozoa were discarded.
Digital images of the different luminal cell types and mature spermatozoa were acquired with a digital camera Nikon DS-FI1 connected with the control unit DS-L2 and mounted on an optical microscope Nikon Eclipse 80i (Nikon, Shinjuku, Japan). The measurements were made using the program Tpsdig2.

\section{Results}

The morphology of the testes was similar in all examined species. The paired testes were semi-translucent organs characterized by a large central lumen and a thin wall (Fig. 1A-C). The latter consisted of the germinal epithelium and a thin vascularized tunica albuginea (Figs 1A-C, 2, 3A).

In all examined species, the tissue of the tunica albuginea was continuous and did not pierce inside the organ, where intergerminal compartments were not observed. (Fig. 1A). The tunica albuginea had about the same thickness as the germinal epithelium and was characterized by connective tissue, rich in muscle fibres and blood vessels. (Figs 1A-C, 2). Fluorescent microscopic analysis on $S$. abaster testes showed that the muscle fibres were disposed in two layers: the internal layer, characterized by fibres oriented perpendicularly to the main axis of the testis, formed a continuous muscular sheath, and the external layer, with only few longitudinal fibres, formed an irregular weft (Fig. 2).

Moreover, between the tunica albuginea and the germinal epithelium, testes of all species had small groups of globular cells resting on the external surface of the basal membrane were visible (Fig. 1B). These cells, analysed in $S$. abaster and $S$. acus using the transmission electron microscopy, had rounded nuclei with one or two large nucleoli. Their cytoplasm was rich in both mitochondria with tubular crests and vesicles of smooth endoplasmic reticulum (Fig. 1D-E).

In all examined species, the germinal epithelium had the typical organization in spermatocysts, which were formed by germ cells enveloped by Sertoli cells, resting on the basal membrane (Figs 1A-C, 3). Sertoli cells were elongated and flat cells characterized by small nuclei of irregular shape (Figs 1B, 3). The transmission electron microscopic analysis on $S$. acus and $S$. abaster testes showed that, in both species, the Sertoli cells cytoplasm appeared more electron-dense than that of germ cells and contained mitochondria, both rough and smooth endoplasmic reticulum, free ribosomes and microvilli-like projections of the surface facing the lumen (Fig. 3B). Moreover, Sertoli cells of the same spermatocysts were joined together with tight-like junctions (Fig. 3B). Along the entire length of the testis, spermatocysts contained spermatogonia and primary spermatocytes (Figs 1A-C, 3). The latter were recognizable by the presence of numerous synaptonemal complexes (Fig. 3C-D). Neither secondary spermatocytes nor spermatids were observed.

In all examined species, inside the testicular lumen, large spherical cells and spermatozoa were embedded in a fibrouslike secretion (Figs 1A-C, 4-7). Two types of spherical cells, 
Fig. 1-A-C. Light micrographs of Syngnathus tenuirostris testis. - A. Transversal section showing large central testicular lumen and thin wall. - B-C. High magnification of the testis wall showing germinal epithelium, tunica albuginea and albuginea's basal cell. D-E. Transmission electron micrographs of Syngnathus acus testis.-D. Albuginea's basal cell. - E. High magnification of adjacent albuginea's basal cells. (AC) albuginea's basal cell, (arrow) spermatogonia, (arrowheads) cellular junctions, (BM) basal membrane, (FS) fibrous secretion, (GE) germinal epithelium, (L) testis lumen, (M) mitochondria, $(\mathrm{N})$ nucleus, (SC) Sertoli cell, (Sp) spermatocytes, (TA) tunica albuginea, (W) wall. Scale bar: $\mathbf{A}=88 \mu \mathrm{m}, \mathbf{B}=26 \mu \mathrm{m}, \mathbf{C}=18 \mu \mathrm{m}$, $\mathbf{D}=186 \mathrm{~nm}, \mathbf{E}=70 \mathrm{~nm}$.
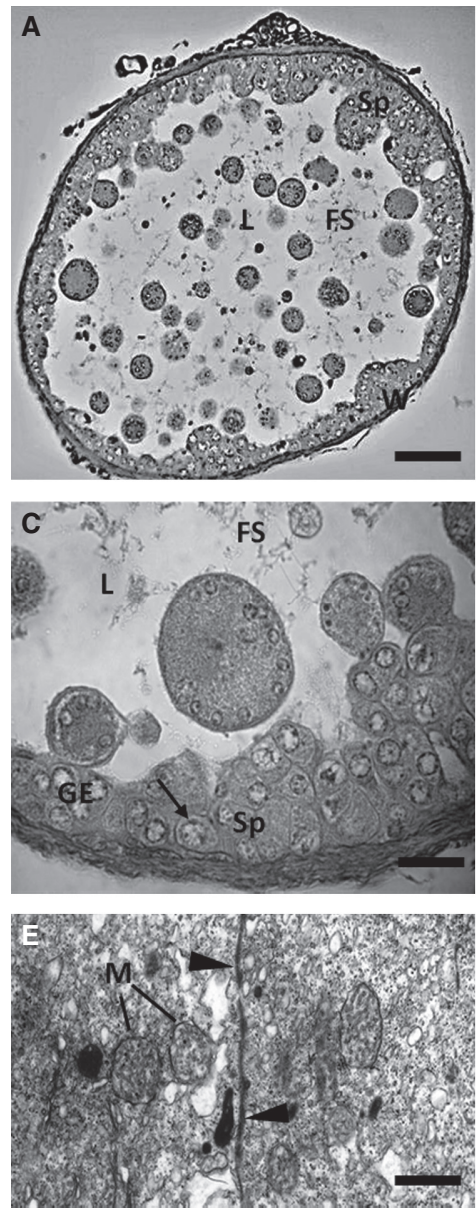
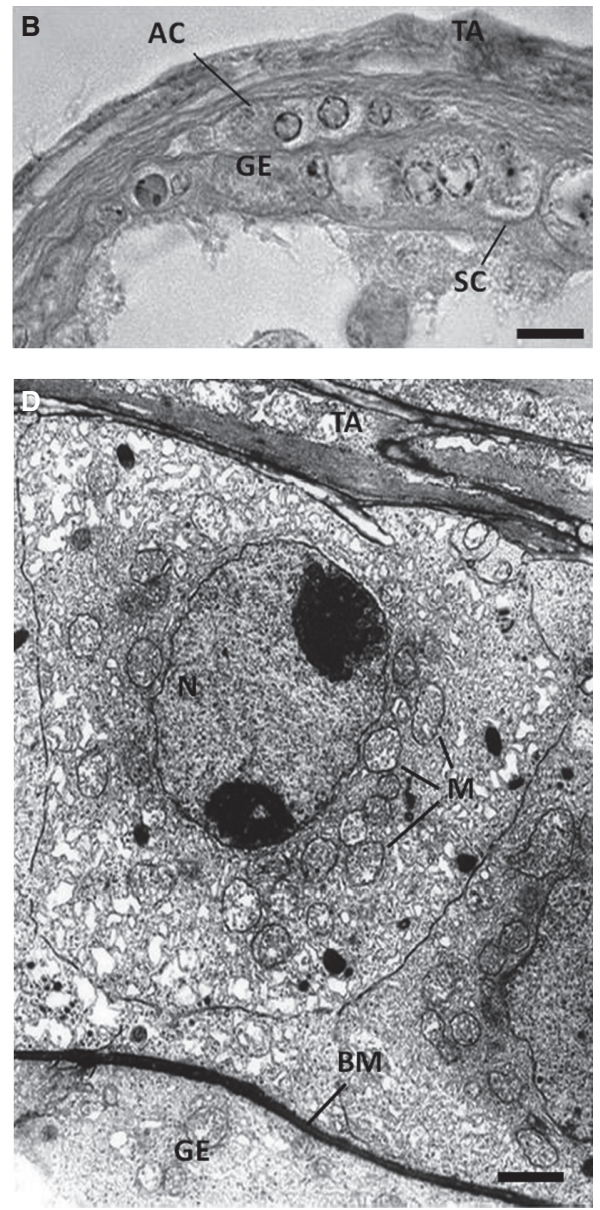

aflagellate and flagellate cells, were recognizable. In $S$. abaster, both cellular types were variable in size (diameter of $20 \mu \mathrm{m}$ in average) and showed one, two or more nuclei (Figs 1A,C, 3, 4-6).

The aflagellate cells had the cytoplasm rich in droplets of different size and density. This made the observation of the nuclei difficult, which were well recognizable using a fluorescent nuclear dye (Fig. 4A,B). All aflagellate cells had nuclei $(n=30)$ of the same size $(9 \pm 0.64 \mu \mathrm{m})$ and morphology, and they occupied most of the cell volume (Fig. 4A,B). In contrast, the flagellate cells showed a less amount of cytoplasmic globules and had nuclei localized at the periphery (Figs 4C-F, 5, 6). These cells were unquestionably developing spermatids, and their nuclei were always characterized by a well-developed nuclear fossa, to which corresponded an emerging flagellum (Figs 4C-F, 6). Mono-, bi- and multiflagellate cells were visible (Figs 4C-F, 5-6). Of 60 flagellated cells, obtained by different slides of the same specimen of $S$. abaster and analysed by light microscopy, only $2 \%$ had a single nucleus, $32 \%$ showed two nuclei, about $6 \%$ had more than ten nuclei, and the remaining $60 \%$ had a variable number of nuclei, from 3 to 10 .
In all examined species, on the basis of nuclear morphology, young, intermediate and late spermatids were distinguished. In $S$. abaster, young spermatids had spherical nuclei of $7.3 \pm 1.09 \mu \mathrm{m}$ in diameter, with one or two spherical dots of nucleolus-like appearance (Fig. 6A). Zones of condensed chromatin were particularly visible at the periphery of the nucleus and in the nuclear fossa region (Figs 4D, 6A).

The intermediate spermatids had smaller nuclei of $3.19 \pm 0.57 \mu \mathrm{m}$, still spherical in shape and similar morphology, but inside them the nucleolus-like dots were no more evident (Fig. 6B,C). The late spermatids had nuclei of subspherical shape $(3.59 \pm 0.36 \mu \mathrm{m})$ and chromatin uniformly condensed (Fig. 6D,E).

Mature sperm were measured in Syngnathus abaster and $S$. typhle only (Figs 4G, 7). In both species, they were elongated monoflagellate cells with flagella of several tens of microns $(54.82 \pm 3.32 \mu \mathrm{m}, \quad n=200) \quad$ in $\quad$ S. abaster and $(58.37 \pm 2.7 \mu \mathrm{m}, n=17)$ in $S$. typhle. They were characterized by a cylindrical head occupied for most of its length by the nucleus of $3.25 \pm 0.14 \mu \mathrm{m}(n=200)$ in $S$. abaster and of $3.35 \pm 0.29 \mu \mathrm{m}(n=17)$ in $S$. typhle. A short midpiece was evident (Fig. 7A-C, insert). 

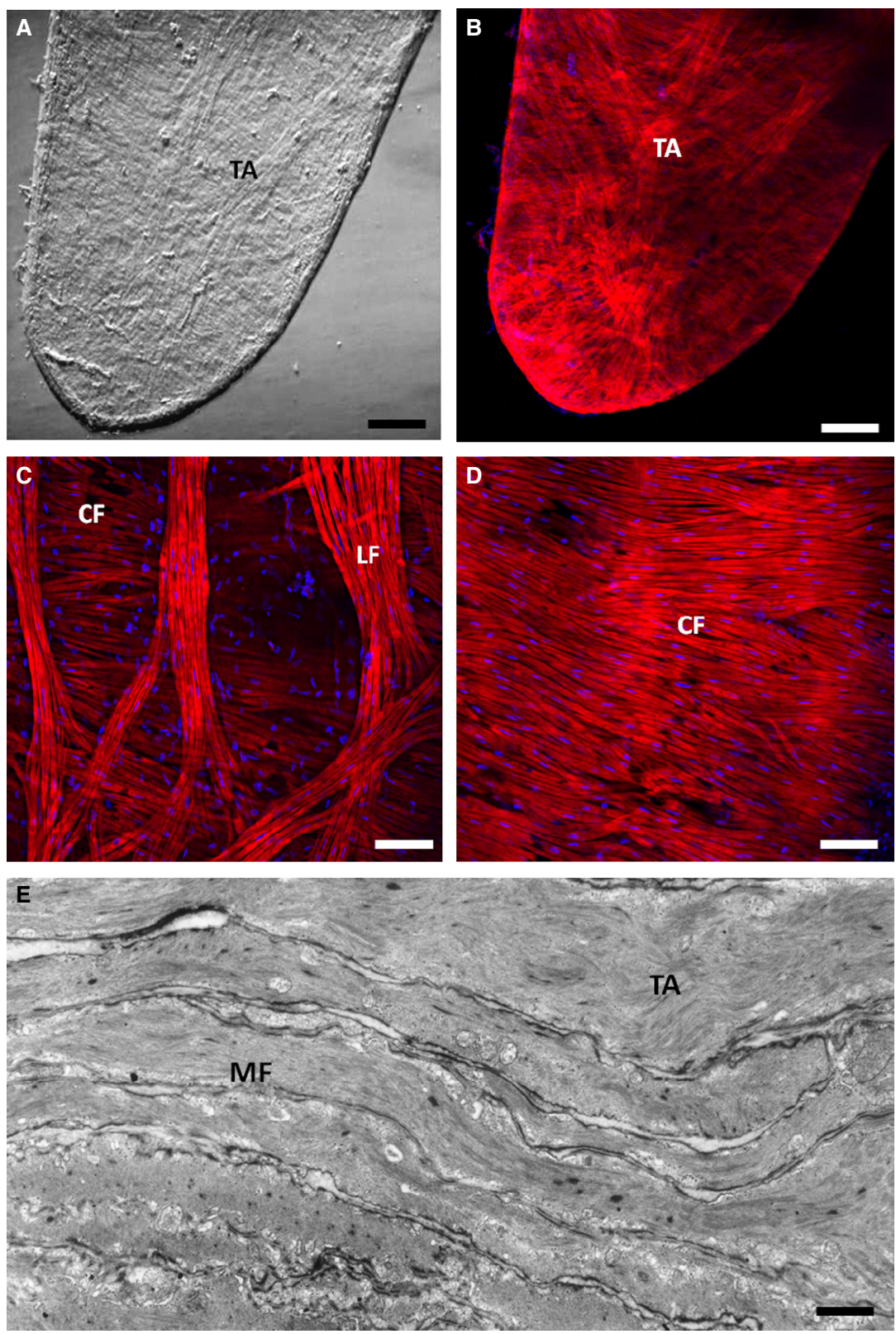

Fig. 2-A. Light micrographs of the apical portion of Syngnathus abaster testis. - B. Confocal laser Scanning Microscopy (CLSM) images of the same portion of testis showing the $\mathrm{F}$-actin localization in the tunica albuginea muscular sheaths. - C-D. High magnification of the same testis portion showing the doubles fluorescent stain with nuclei in blue and F-actin filament in red. - C. Note the different arrangement of muscular fibres in the two internal and external sheaths. - E.

Transmission electron micrograph of muscle fibres characterizing the tunica albuginea of $S$. acus testis. (CF) circular muscular fibres, (LF) longitudinal muscle fibres, $(\mathrm{MF})$ muscle fibres, (TA) tunica albuginea. Scale bar: $\mathbf{A}-$ $\mathbf{B}=71 \mu \mathrm{m}, \mathbf{C}-\mathbf{D}=18 \mu \mathrm{m}, \mathbf{E}=120 \mathrm{~nm}$.

\section{Discussion}

In all syngnathid species here analysed, the testis atypically consists of a single and continuous germinal compartment surrounded by a single and continuous somatic compartment. Each testis appears as a tubular organ characterized by a unique testicular lumen surrounded by two concentric layers, the thick tunica albuginea and the germinal epithelium, separated by the basement membrane. In all other vertebrates, from fish to mammals (see Schulz et al. 2010), the testis has a more complicated organization being the germinal compartment generally arranged in numerous germinal units, amongst which numerous intergerminal extensions of somatic compartment are present.

The tunica albuginea of syngnathids testes contains blood vessels, connective cells and numerous smooth muscle fibres. Moreover, small groups of cells are visible in close contact with the external surface of the basal membrane. Large cells surrounded by connective tissue have been also seen in M. brachyurus lineatus, but they were interpreted as primary spermatogonia (Miranda-Marure et al. 2004). However, we retain that both their localization and cytoplasmic characteristics, such as mitochondria with tubular crests and abundant vesicle of smooth endoplasmic reticulum, are consistent with the interstitial Leydig cells. 
Fig. 3-A. Light microscopy image of Syngnathus abaster testis showing spermatocysts containing spermatocytes and polynucleated cells inside the lumen. $-\mathbf{B}$. Transmission electron micrograph of Syngnathus acus spermatocysts with germ cells enveloped by Sertoli cells. - C. Transmission electron micrograph of primary spermatocytes of $S$. acus. - D. High magnification of synaptonemal complex. (Arrow) basal membrane, (arrowheads) synaptonemal complex, (GC) germ cells, (J) tight-like junctions, (L) lumen, (MV) microvilli-like projections, (PC) polynucleated cell, (SC) Sertoli cells, (Sp) spermatocytes. Scale bar: $\mathbf{A}=16 \mu \mathrm{m}, \mathbf{B}=1 \mu \mathrm{m}$, $\mathbf{C}=130 \mathrm{~nm}, \mathbf{D}=30 \mathrm{~nm}$.
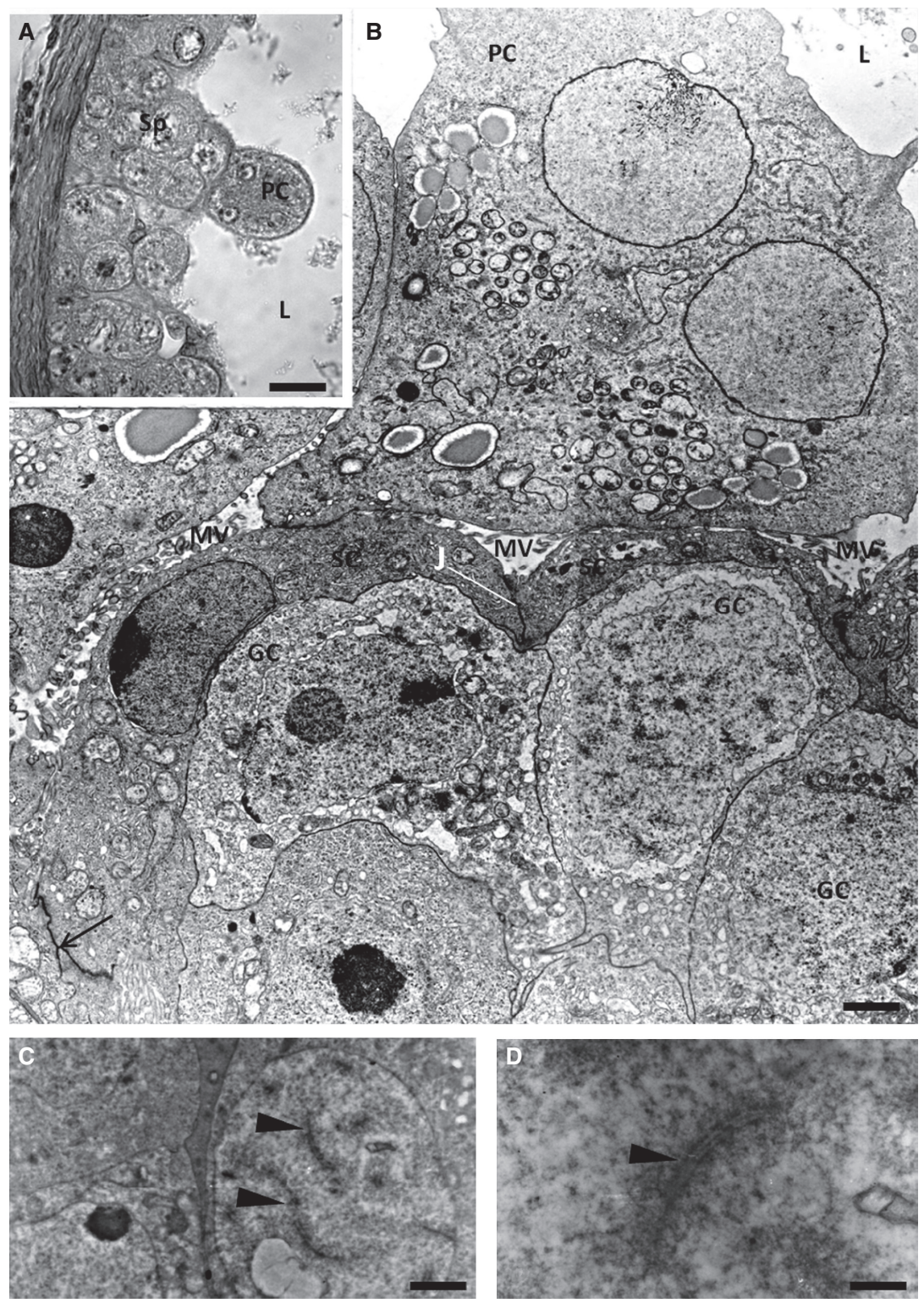

Because of the presence of an atypical permanent lumen, the syngnathids testis was defined as belonging to the tubular type (Carcupino et al. 1999). However, according to the better elucidated definition reported in Parenti and Grier (2004), testes of tubular type are only those in which 'the germinal compartments do not terminate at the testis periphery, but form highly branched, anastomosing loops or tubules'. Instead, testes of lobular type are those in which 'the germinal compartments may form anastomosing networks proximally, but distally they extend to the periphery of the testis and terminate blindly'. On this basis, testes of the syngnathids here analysed, must be included in the lobular type, as are formed by a single germinal compartment, without forming any kind of anastomosing networks and terminating blindly.
Spermatogonia are clearly distributed along the entire length of the testis, so we may confirm that also in these representatives of Syngnathidae, the testis organization is of the unrestricted lobular type, typically found throughout the Neoteleostei, except for the atherinomorphs (Parenti and Grier 2004).

Both the light and electron microscopic analyses definitely demonstrate that at least in Syngnathus species, the germinal epithelium has the typical tripartite organization, in which germ cells surrounded by Sertoli cells form spermatocysts resting on the basal lamina. Sertoli cells are easily recognizable from germ cells because of their elongated and flat shape, small nuclei of irregular shape and their capacity to form tight-like junctions with adjacent Sertoli cells belonging to the same spermatocysts. 

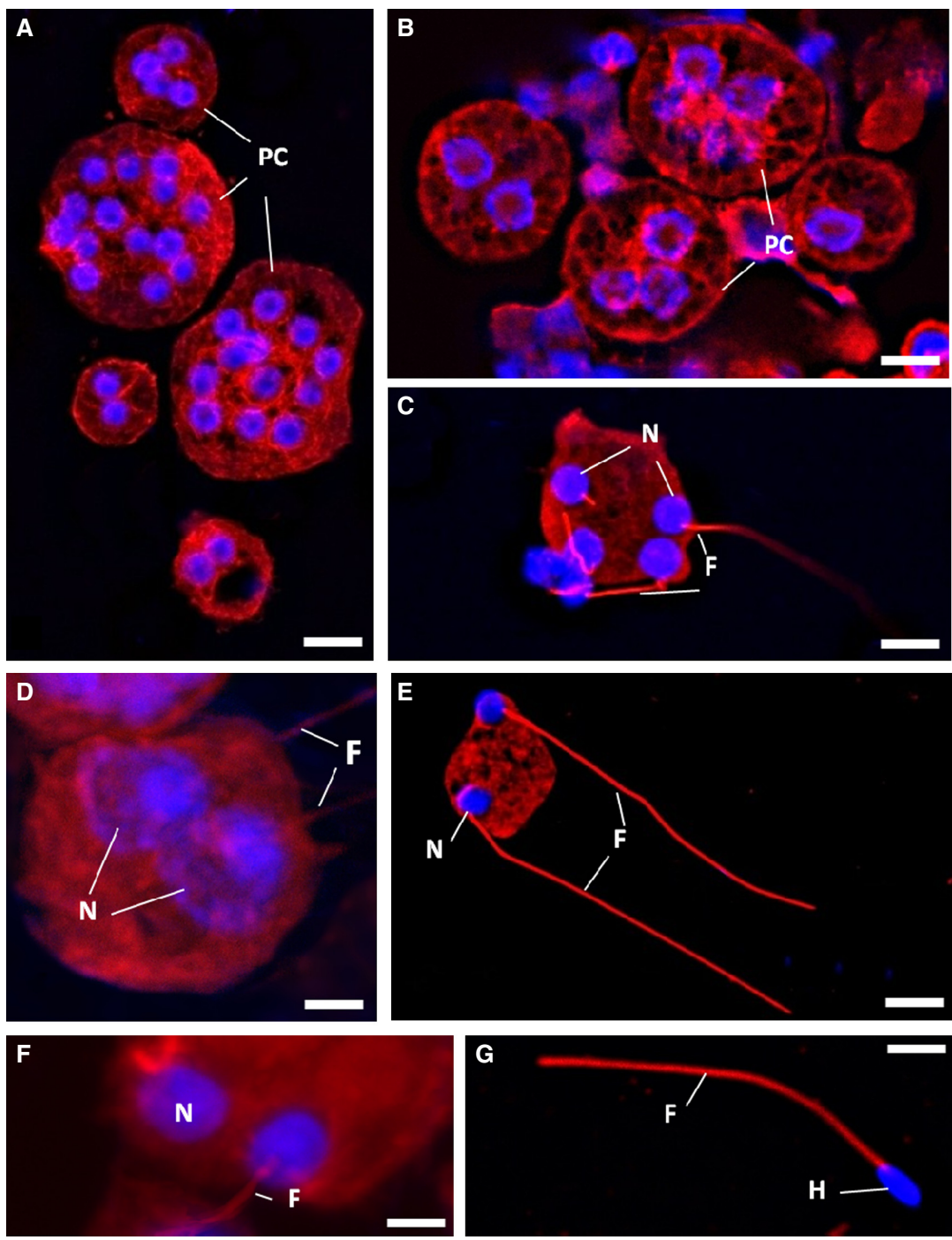

Fig. 4 - Confocal laser scanning microscopy (CLSM) images of luminal cells obtained from Syngnathus abaster testes showing the dual fluorescent stain with nuclei in blue and microtubules in red. - A-B. Aflagellate polynucleated cells. - C. Polynucleated spermatids showing nuclei localized at the periphery of the cells and emerging flagella. - D-F.

Spermatids in different developmental stages. -D. Young spermatids with nuclei characterized by zones of condensed chromatin particularly visible at the nuclear periphery and in the fossa region. - E. Intermediate spermatids with more condensed nuclei. - F. Late spermatids with nuclei of subspherical shape. -G. Mature sperm with cylindrical head. (F) flagella, $(\mathrm{H})$ head, $(\mathrm{N})$ nuclei, $(\mathrm{PC})$ polynucleated cells. Scale bar: $\mathbf{A}=15 \mu \mathrm{m}$, $\mathbf{B}=3 \mu \mathrm{m}, \mathbf{C}=9 \mu \mathrm{m}, \mathbf{D}=2 \mu \mathrm{m}$, $\mathbf{E}=9 \mu \mathrm{m}, \mathbf{F}=2 \mu \mathrm{m}, \mathbf{G}=3 \mu \mathrm{m}$.
In agreement with previous data (Carcupino et al. 1999), in the germinal epithelium of all reproductive males here analysed, the spermatocysts only contain spermatogonia and primary spermatocytes. Developing spermatids are recognizable by both the presence of flagella emerging from a deep nuclear fossa and nuclei characterized by different degrees of chromatin condensation. They are only visible inside the testis lumen together with matures sperm. These data confirm that, at least in Syngnathus pipefishes, the spermatogenetic process is of semicystic type.

Generally, the spermatogenesis of bony fish is cystic, and therefore, the process takes place entirely inside the cyst, when the cyst breaks the spermatozoa are released into the lumen. In contrast, in the semicystic type, the cyst ruptures at the spermatocyte or spermatid stage, so germ cells only partly develop inside the cyst (Mattei and Mattei 1978). This type of spermatogenesis may result in asynchronous maturation of spermatids, thereby reducing the number of simultaneously mature sperm.

Semicystic spermatogenesis was described for the first time in some Gobiesocidae (Mattei and Mattei 1978) and is currently known in several teleostean groups, such as Blenniidae (Lahnsteiner and Patzner 1990; Lahnsteiner et al. 1990; Giacomello et al. 2008), Opistognathidae (Manni and Rasotto 1997), Channidae (Srivastava and Singh 1994), Gobiidae (Mazzoldi 2001), the Ciprinodontiformes Fundulus heteroclitus (Selman and Wallace 1986), the Ophidiiformes Ophidion sp. (Mattei et al. 1993) and Ophidion barbatum (Hernández et al. 2005), the Lofiiformes Lophiomus setigerus (Yoneda et al. 1998a), some Scorpeniformes (Muñoz et al. 2002; Sàbat 2002; Sàbat et al. 2009), the Siluriformes, Malapterurus electricus (Shahin 2006), the Caraciformes, Acestrorhynchus lacustris (Bazzoli and Godinho 1991), Bryconops affinis (Andrade et al. 2001) and H. marginatus (Magalhaes et al. 2011), and the 
Fig. 5-Scanning electron microscopy images of flagellate cells obtained from Syngnathus abaster testis lumen. - A-C. Mono-, bi- and multiflagellate spermatids. (F) flagella. Scale bar: $\mathbf{A}=2.7 \mu \mathrm{m}$, Insert $=1.3 \mu \mathrm{m}, \mathbf{B}=1 \mu \mathrm{m}$, $\mathbf{C}=1 \mu \mathrm{m}$.
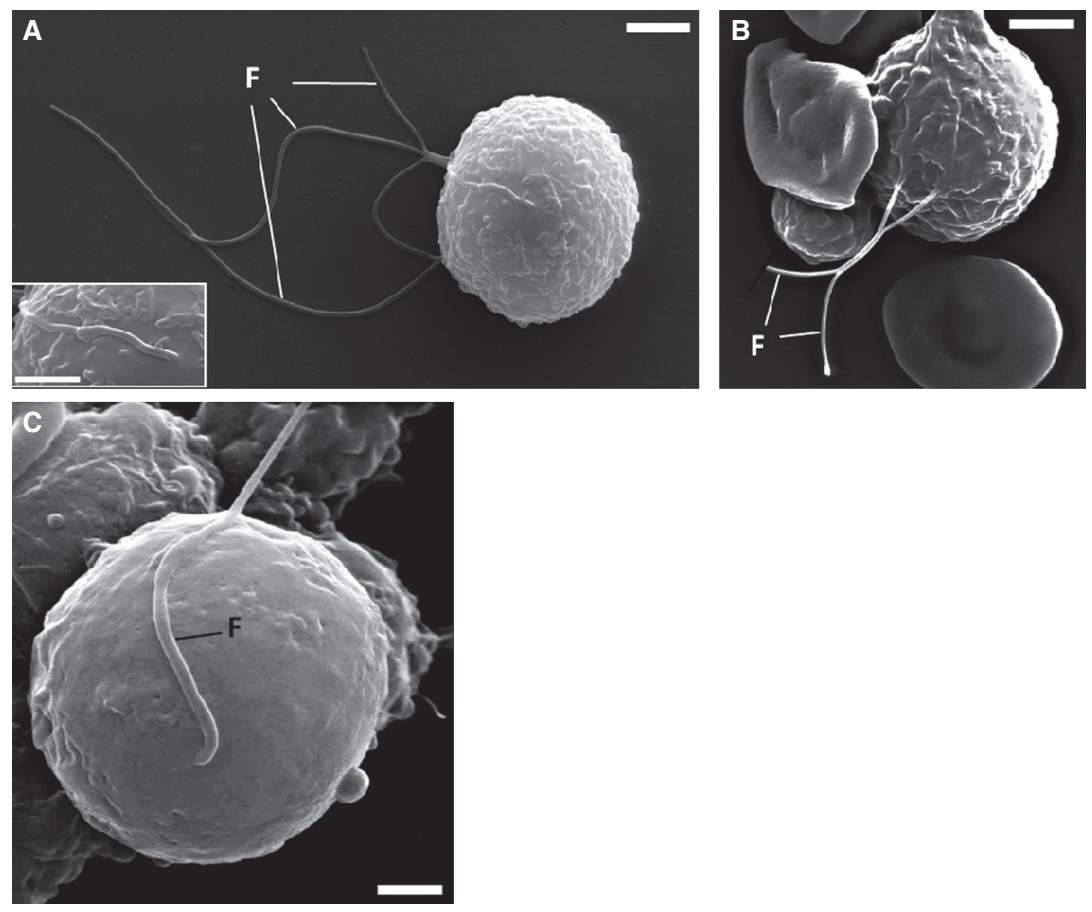

Pleuronectiformes, Solea senegalensis (García-López et al. 2005).

Several hypotheses have been formulated regarding the functional significance of semicystic spermatogenesis. This type of spermatogenesis leads to a reduced number of simultaneously mature sperm, and it has been interpreted as one of the possible mechanisms evolved to reduce the cost of sperm production. This is the case of species, such as syngnathids, performing male parental care, in which the energies devoted to reproduction cannot all be invested by the male in sperm production. (Manni and Rasotto 1997; Giacomello et al. 2008). This mechanism seems therefore to be crucial in those species in which, a small ejaculate size is justified by their low fecundity, monogamous mating system, absence of sperm competition and presence of male parental care, such as some Opistognathidae (Rasotto et al. 1992; Marconato and Rasotto 1993) and Gobiidae (Mazzoldi 2001). However, the asynchronous maturation of spermatids, thereby reducing the number of simultaneously mature sperm, related to a spermatogenetic process of the semicystic type, has been hypothesized to be also useful in those species showing a promiscuous mating system and/or a long-lasting egg deposition (see some blennies). In such species, the males are forced to parcel out their sperm expenditure during mating into several successive ejaculates, releasing only limited portions of sperm at each ejaculation (Giacomello et al. 2008). All syngnathid species have very small ejaculate size, low fecundity, male parental care, absence of sperm competition, and their mating system varies from monogamy to different types of polygamy (Wilson et al. 2003; Sanna et al. 2008).
It should be also mentioned that the semicystic spermatogenesis has been associated to other functions. According to Muñoz et al. (2002), in some species (see Ophidion marginatum, Lophiomus setigerus and Scorpena notata) that lay eggs within a gelatinous mass, such as syngnathids, (Fahay 1992; Yoneda et al. 1998b), this type of spermatogenesis could be in some way related to the secretion of abundant thick seminal fluid, having function in keeping the spermatozoa together, facilitating fertilization of the whole egg mass. In other species, such as Blenniidae, the male gonads exhibit a peculiar organization, consisting of a strictly spermatogenetic part (testicular lobules or testis) and a glandular part (testicular gland) (Lahnsteiner et al. 1990; Richtarski and Patzner 2000). These species show spermatogenesis of the semicystic type and a high interspecific variability associated with the level of semicystic spermatogenesis (with spermatids released at different stages of maturity) (Lahnsteiner and Patzner 1990) and with the relative development of the two gonad parts (Richtarski and Patzner 2000). Species in which spermatids are released at a very late stage of maturation have a reduced testicular gland, which has been supposed to be exclusively related to the seminal fluid production. In contrast, species where spermatids are released at an earlier stage of maturation, have more developed testicular gland involved in both seminal fluid production and metabolic supply of germ cells (Giacomello et al. 2008). In relation to this last aspect, it should not be forgotten that in the semicystic spermatogenetic process, Sertoli cells cannot regulate and support the metabolites transfer towards the developing germ cells, when the latter are free inside the 

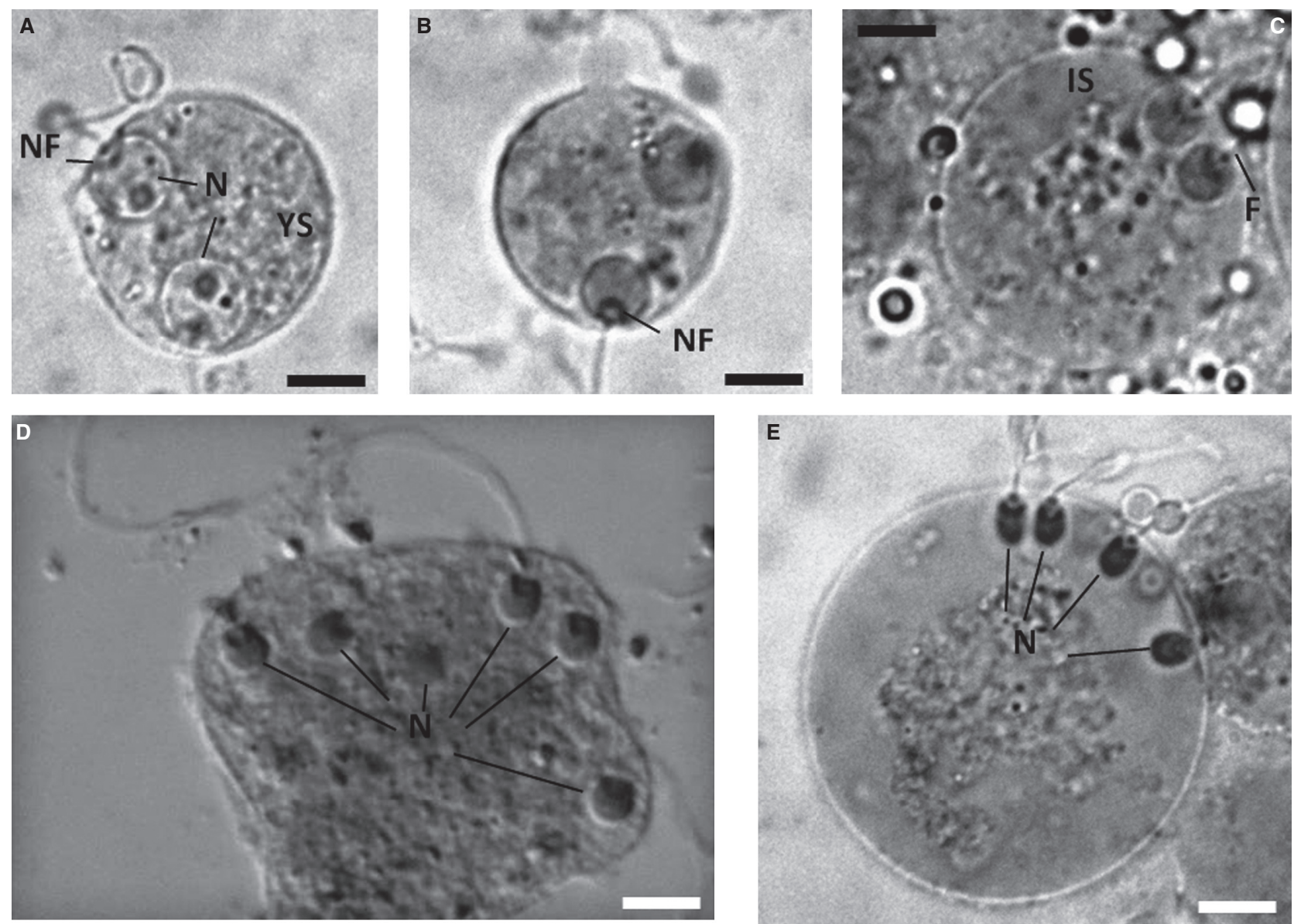

Fig. 6-A-E. Light microscopy images of $S$. abaster spermatids stained with acetic orcein at different developmental stages. -A. Young spermatids. - B-C. Intermediate spermatids; - D-E. Late spermatids. (F) flagella, (IS) intermediate spermatids, (N) nucleus, (NF) nuclear fossa, (YS) young spermatids. Scale bar: $\mathbf{A}=11 \mu \mathrm{m}, \mathbf{B}=10 \mu \mathrm{m}, \mathbf{C}=12 \mu \mathrm{m}, \mathbf{D}=10 \mu \mathrm{m}, \mathbf{E}=12 \mu \mathrm{m}$.

lumen. So, their metabolic demands depend on their stage of maturity at the moment of the cyst rupture.

In the typical semicystic spermatogenesis, spermatocytes and/or spermatids are released after the cytokinesis, amongst isogenetic germ cells, is completed. Therefore, germ cells advance individually through spermiogenesis inside the lumen. As previously documented in Syngnathus abaster and S. acus (Carcupino et al. 1999), and here confirmed in the same and in other species of the same genus, developing germ cells inside the lumen are mono- and, more frequently, polynucleate and polyflagellate cells. Individualization of mature sperm seems to occur at the end of spermiogenesis, so the cytokinesis seems to be abolished or at least delayed. Moreover, together with developing spermatids and mature spermatozoa, another type of polynucleated cells is present inside the testicular lumen of Syngnathus species. These cells are aflagellate and characterized by a large amount of cytoplasmic droplets. Large droplets-containing cells have also been reported in $S$. schlegeli testis (Watanabe et al. 2000). In this species, how- ever, this kind of cells seems to be only recognizable inside the germinal epithelium. In contrast, in the reproductive males here analysed, these cells are frequently observed free into the testicular lumen, but they are also recognizable coming out from the epithelium. On the basis of these data, the large droplets-containing cells of $S$. schlegeli testis are likely of the same cellular type reported here. The apparent discrepancy in their localization may only be due to a different developmental stage of the males analysed.

A smaller amount of droplets of different size and electron density may be also recognizable in the cytoplasm of developing polynucleated and flagellate spermatids, so the present data seem to support the hypothesis (Carcupino et al. 1999) that aflagellate cells may be germ cells. These cells could therefore represent the youngest germ cells released inside the lumen at the spermatocyte or very early spermatid stage, after having accumulated a large amount of material in form of droplets. These droplets progressively reduce in size and number during the germ cell maturation. 


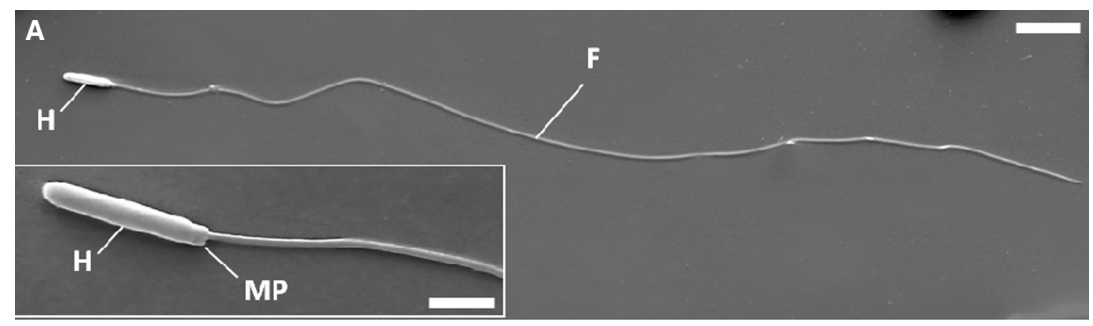

Fig. 7-A, Insert. Scanning electron micrographs of mature sperm of Syngnathus abaster. -B-C. Mature sperm stained with toluidine Blue of and $S$. abaster and $S$. typhle respectively. -D. Cryosection of $S$. abaster testis showing several sperm inside the lumen. $(\mathrm{F})$ flagellum, (H) head, (MP) short mid-piece. Scale bar: $\mathbf{A}=7.5 \mu \mathrm{m}$, Insert $=1.3 \mu \mathrm{m}$, $\mathbf{B}=5 \mu \mathrm{m}, \mathbf{C}=2.4 \mu \mathrm{m}, \mathbf{D}=6 \mu \mathrm{m}$
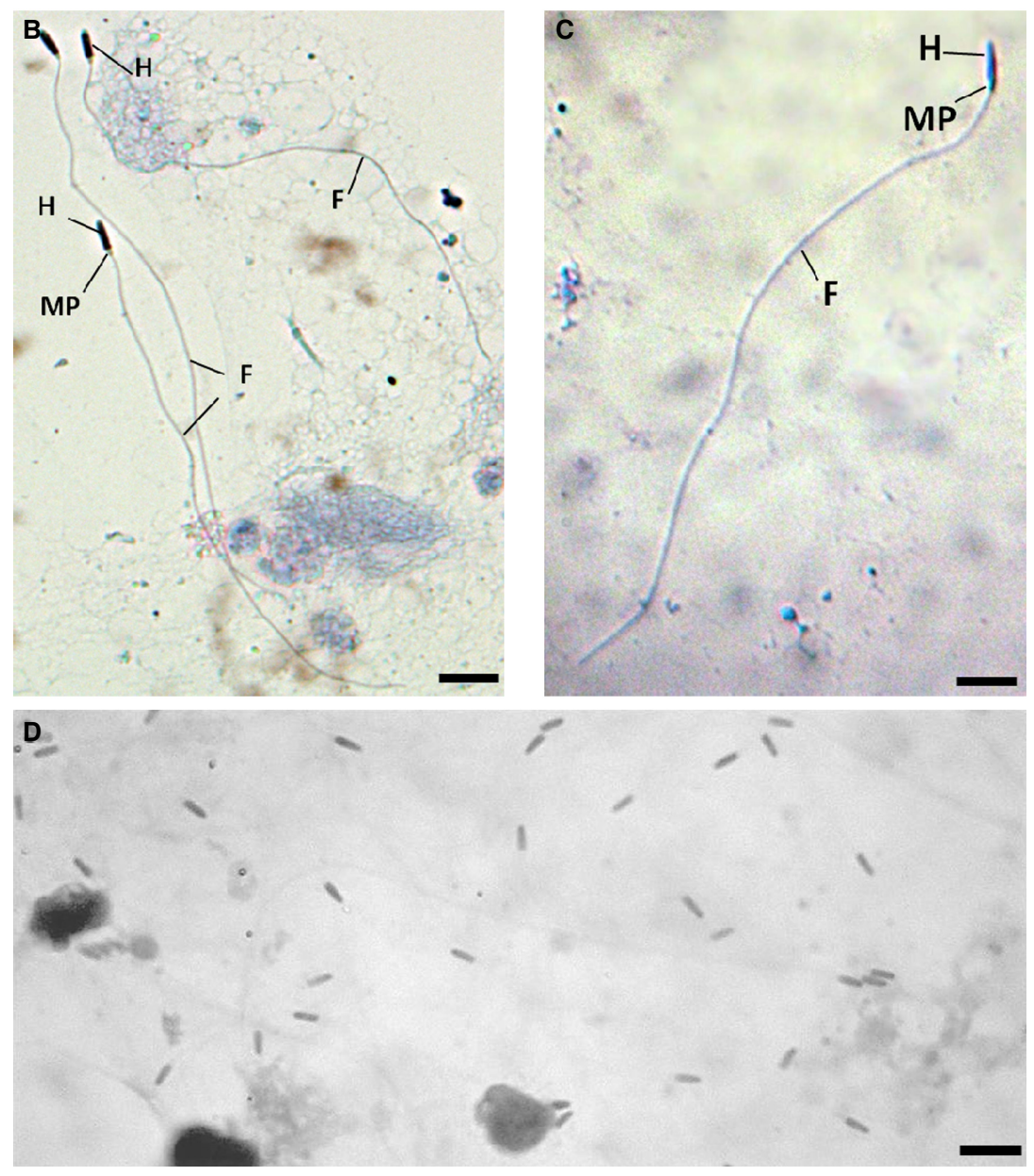

No glandular structures have been identified in the testis and along the sperm ducts of Syngnathus species (data not shown). Consequently, we consider that the large amount of droplets accumulated in the cytoplasm of germ cells could have a dual role in: i) the formation of an abundant and fibrous seminal fluid, which could have the function for trapping the very low number of mature sperm produced by syngnathids (Watanabe et al. 2000; Van Look et al. 2007; Biagi et al. 2008; Dzyuba et al. 2008), avoiding sperm loss during mating and ii) the metabolic supply of the developing germ cells, which are released in a very early spermatogenetic stage.

In the light of these two possible functions, it could be also interpreted the functional significance of the delayed cytokine- sis observed in the semicystic spermatogenesis of Syngnathus species. An early cytoplasmic division amongst isogenetic cell could lead to a reduction in the amount of cytoplasm and organelles. Consequently, the production and accumulation of material useful for the energy requirements of each germ cell and the production of a sufficient amount of seminal fluid may be endangered.

In agreement with our previous data (Carcupino et al. 1999), only one type of sperm has been recognized in all Syngnathus species here analysed. The data on mature sperm morphology previously reported in Syngnathidae, such as the aflagellate sperm in M. brachyurus lineatus (Miranda-Marure et al. 2004) and the dimorphic flagellate sperm in S. schlegeli and Hippocampus kuda (Watanabe et al. 2000; Van Look et al. 
2007) that are conflicting, may be therefore due to the semicystic spermatogenesis, which determines the simultaneous presence of different kinds of flagellate and aflagellate cells in the testicular lumen.

The most particular feature of mature sperm is the elongated shape of the head, a morphology that has also been observed in some Blenniidae (Lahnsteiner et al. 1990) in Lepadogaster lepadogaster (Mattei and Mattei 1978), and in Ophidion barbatum (Hernández et al. 2005), all species with external fertilization and semicystic spermatogenesis. In general, spermatozoa with elongated heads are related to internal fertilization (Jamieson and Leung 1991), an explanation that does not match any of the mentioned species. According to Burns et al. (1995), the elongated nucleus may also facilitate the storage of the spermatozoa in the testicular ducts. Nevertheless, in the specific cases of $O$. barbatum (Hernández et al. 2005) and Syngnathus species (data not shown), no packaging of spermatozoa was observed. Because neither have these species internal fertilization nor spermatophores production, a third possibility to explain the particularly elongated head of sperm could be their need to cross through the gelatinous mass of maternal origin to reach the eggs.

\section{References}

Ah-King, M., Elofsson, H., Kvarnemo, C., Rosenqvist, G. and Berglund, A. 2006. Why is there no sperm competition in a pipefish with externally brooding males? Insights from sperm activation and morphology fournal of Fish Biology 68: 1-5.

Andrade, R. F., Bazzoli, N., Rizzo, E. and Sato, Y. 2001. Continuous gametogenesis in the neotropical freshwater teleost, Bryconops affinis (Pisces: Characidae). Tissue and Cell 33: 524-532.

Bazzoli, N. and Godinho, H. 1991. Reproductive biology of the Acestrorhynchus lacustris (Reinhardt, 1874) (Pisces: Characidae) from Três Marias Reservoir Brazil. Zoologischer Anzeiger 226: 285-297.

Biagi, F., Addis, A., Floris, A., Corso, G., Franzoi, P., Torricelli, P. and Carcupino, M. 2008. Sperm number and structure of the black-striped pipefish Syngnathus abaster (Teleostei, Syngnathidae). In: Collodel, G. and Moretti, E. (Eds): Sperm Morphology and Pathology, pp. 1-11. Research Signpost, Kerala, India.

Burns, J. R. and Weitzman, S. H. 2006. Intromittent organ in the genus Monotocheirodon (Characiformes: Characidae). Copeia 3: 529-534.

Burns, J. R., Weitzman, S. H., Grier, H. and Menezes, N. A. 1995. Internal fertilization, testis and sperm morphology in glandulocaudine fishes (Teleostei: Characidae: Glandulocaudinae). Fournal of Morphology 224: 131-145.

Burns, J. R., Weitzman, S. H., Malabarba, L. R. and Meisner, A. D. 2000. Sperm modifications in inseminating ostariophysan fishes, with new documentation of inseminating species. In: Norberg, B., Kjesbu, O. S., Taranger, G. L., Andersson, E. and Stefansson, S. O. (Eds): Proceedings of the Sixth International Symposium of Reproduction and Physiology of Fishes, p. 255. Bergen, Norway.

Carcupino, M., Baldacci, A., Corso, G., Franzoi, P., Pala, M. and Mazzini, M. 1999. Testis structure and symplastic spermatid formation during spermatogenesis of pipefishes. Fournal of Fish Biology 55: 334-353.

Dzyuba, B. B., Van Look, K. J. W., Kholodnyy, V. S., Satake, N., Cheung, S. and Holt, W. V. 2008. Variable sperm size and motility activation in the pipefish, Syngnathus abaster; adaptations to paternal care or environmental plasticity? Reproduction, Fertility and Development 20: 474-482.

Fahay, M. P. 1992. Development and distribution of cusk eel eggs and larvae in the Middle Atlantic Bight with a description of Ophidion robinsi $\mathrm{n}$. sp. (Teleostei: Ophidiidae). Copeia 3: 799-819.

García-López, Á., Martínez-Rodríguez, G. and Sarasquete, C. 2005. Male reproductive system in Senegalese sole Solea senegalensis (Kaup): anatomy, histology and histochemistry. Histology and Histopathology 20: 1179-1189.

Giacomello, E., Neat, F. C. and Rasotto, M. B. 2008. Mechanisms enabling sperm economy in blenniid fishes. Behavioral Ecology and Sociobiology 62: 271-680.

Hernández, M. R., Sàbat, M., Muñoz, M. and Casadevall, M. 2005. Semicystic spermatogenesis and reproductive strategy in Ophidion barbatum (Pisces, Ophidiidae). Acta Zoologica 86: 295-300.

Jamieson, B. G. M. 1991. Fish Evolution and Systematics: Evidence from Spermatozoa. Cambridge University Press, Cambridge, p. 319

Jamieson, B. G. M. and Leung, L. K. P. 1991. Introduction to fish spermatozoa and the micropyle. In: Jamieson, B. G. M. (Ed.): Fish Evolution and Systematics: Evidence from Spermatozoa, pp. 5672. Cambridge University Press, Cambridge.

Lahnsteiner, F. and Patzner, R. A. 1990. Spermiogenesis and structure of mature spermatozoa in blenniid fishes (Pisces, Blenniidae). Fournal of Submicroscopic Cytology and Pathology 22: 565-576.

Lahnsteiner, V., Richtarski, U. and Patzner, R. A. 1990. Functions of the testicular gland in two bleniid fishes, Salaria (=Blennius) pavo and Lipophrys (=Blennius) dalmatinus (Blenniidae, Teleostei) as revealed by electron microscopy and enzyme histochemistry. Fournal of Fish Biology 37: 85-97.

Magalhaes, A. L. B., Andrade, R. F., Gomes, B. V. C., Perini, V. R., Rizzo, E. and Bazzoli, N. 2011. Ultrastructure of the semicystic spermatogenesis in the South American freshwater characid Hemigrammus marginatus (Teleostei, Characiformes). Fournal of Applied Ichthyology 27: 1041-1046.

Manni, L. and Rasotto, M. B. 1997. Ultrastructure and histochemistry of the testicular efferent duct system and spermiogenesis in Opistognathus whitehurstii (Teleostei, Trachinoidei). Zoomorphology 117: 93-102.

Marconato, A. and Rasotto, M. B. 1993. The reproductive biology of Opistognathus whitehurstii (Pisces, Opistognathidae). Biologia Marina Mediterranea 1: 345-348.

Mattei, C. and Mattei, X. 1978.La spermiogenèse d'un poisson téléostéen (Lepadogaster lepadogaster) II. Le spermatozoïde. Biology of the Cell 32: 267-274.

Mattei, X., Siau, Y., Thiaw, O. T. and Thiam, D. 1993. Peculiarities in the organization of testis of Ophidion sp. (Pisces Teleostei). Evidence for two types of spermatogenesis in teleost fish. fournal of Fish Biology 43: 931-937.

Mazzi, V. 1977. Manuale di tecniche istologiche e istochimiche. Piccin-Nuova Libraria, Padova, Italy, p. 750.

Mazzoldi, C. 2001. Reproductive apparatus and mating system in two tropical goby species. Fournal of Fish Biology 59: 16861691.

Meisner, A. D. 2005. Male modifications associated with insemination in teleosts. In: Grier, H. J. and Uribe, M. C. (Eds): Uribe Viviparous Fishes, pp. 165-190. New Life Publications, Homestead, Florida.

Miranda-Marure, M. E., Martínez-Peréz, J. A. and Brown-Peterson, N. J. 2004. Reproductive biology of the opossum pipefish, Microphis brachyurus lineatus, in Tecolutla estuary, Veracruz, Mexico. Gulf and Caribbean Research 16: 101-108. 
Muñoz, M., Casadevall, M. and Bonet, S. 2002. Testicular structure and semicystic spermatogenesis in a specialized ovuliparous species: Scopaena notata (Pisces, Scorpaenidae). Acta Zoologica 83: 213219.

Parenti, L. R. and Grier, H. J. 2004. Evolution and phylogeny of gonad morphology in bony fishes. Integrative and Comparative Biology 44: 333-348.

Rasotto, M. B., Marconato, A. and Shapiro, D. Y. 1992. The reproductive apparatus of two Jawfish species (Opistognathidae) with description of a juxtatesticular body. Copeia 4: 1046-1053

Richtarski, U. and Patzner, R. A. 2000. Comparative morphology of male reproductive systems in Mediterranean blennies (Blenniidae). Fournal of Fish Biology 56: 22-36.

Sàbat, M. 2002. La reproducció de l'escorpora fosca Scorpaena Porcus Linné, (1758). Master Thesis. University of Girona, Girona.

Sàbat, M., Lo Nostro, F., Casadevall, M. and Muñoz, M. 2009. A light and electron microscopic study on the organization of the testis and the semicystic spermatogenesis of the genus Scorpaena (Teleostei, Scorpaenidae). Foumal of Morphology 270: 662-672.

Sanna, D., Addis, A., Biagi, F., Motzo, C., Carcupino, M. and Francalacci, P. 2008. mtDNA control region and D-HPLC analysis: a method to evaluate the mating system in Syngnathidae (Teleostei). Marine Biology 153: 269-275.

Schulz, R. W., Franca, L. R., Lareyre, J. J., LeGac, F., Garcia, H. C., Nobrega, R. H. and Miura, T. 2010. Spermatogenesis in fish. General and Comparative Endocrinology 165: 390-411.

Selman, K. and Wallace, R. A. 1986. Gametogenesis in Fundulus heteroclitus. American Zoologist 26: 173-192.
Shahin, A. A. B. 2006. Semicystic spermatogenesis and biflagellate spermatozoon ultrastructure in the Nile electric catfish Malapterurus electricus (Teleostei: Siluriformes: Malapteruridae). Acta Zoologica 87: $215-227$.

Srivastava, S. J. and Singh, R. 1994. Seasonal changes in the testis of a freshwater murrel, Channa punctatus (Bloch). Naturalia 19: 119130.

Van Look, K. J., Dzyuba, B., Cliffe, A., Koldewey, H. J. and Holt, W. V. 2007. Dimorphic sperm and the unlikely route to fertilisation in the yellow seahorse. Fournal of Experimental Biology 210: 432-437.

Watanabe, S., Hara, M. and Watanabe, Y. 2000. Male internal fertilization and introsperm- like sperm of the seaweed pipefish (Syngnathus schlegeli). Zoological Science 17: 759-767.

Wilson, A. B. and Orr, J. W. 2011. The evolutionary origins of Syngnathidae: pipefishes and seahorses. Fournal of Fish Biology 78: 1603-1623.

Wilson, A. B., Ahnesjö, I., Vincent, A. C. J. and Meyer, A. 2003. The dynamics of male brooding, mating patterns, and sex roles in pipefishes and seahorses (family Syngnathidae). Evolution 57: 13741386.

Yoneda, M., Tokimura, M., Fujita, H., Takesbita, N., Takesbita, K., Matsuyama, M. and Matsuura, S. 1998a. Reproductive cycle and sexual maturity of the angler fish Lophiomus setigerus in the East China Sea with a note on specialized spermatogenesis. Fournal of Fish Biology 53: 164-178.

Yoneda, M., Tokimura, M., Fujita, H., Takeshita, N., Takeshita, K., Matsuyama, M. and Matsuura, S. 1998b. Ovarian structure and batch fecundity in Lophiomus setigerus. Fournal of Fish Biology 52: 94-106. 